\title{
An Innovative Pattern for Management Capacity Cultivation
}

\author{
Qingjun $\mathrm{Wu}$ \\ College of Operation and Management, Qufu Normal University, Rizhao 276826, China \\ E-mail: wuqingjun@yahoo.com.cn
}

\begin{abstract}
Management, as a kind of capacity, should be formed in practice. Currently, however, management majors are mainly taught in knowledge instead of any platform or environment. As a result, students find it hard to convert their management knowledge into real capacity. In order to solve this problem, this article creates an innovative pattern for cultivating students' management capacity.
\end{abstract}

Keywords: Management capacity cultivation, Project team, Innovation

\section{The Current Situation of Management Capacity Cultivation in Management Majors}

Currently, some management courses are offered to management majors, such as management principles, project management, financial management, strategic management, supply chain management, logistic management, operation management, service management, information management, human resource management and so on, which provide basic knowledge for these students while lacking in a platform or environment for students to practice their knowledge, hence resulting in their inability in actual management practice.

It is surely the best way for students to develop their management capacity in actual management of enterprise routines, but it is hardly possible for them. Even if they serve as an intern for a company, they can only stand by to observe and learn the management styles and skills of the leaders there instead of participating in the management process, not to mention management practice. Therefore, it won't work to cultivate students' management capacity through exercitation in companies.

Although the students' union in universities and colleges will help to cultivate students' management capacity, it is available to some, not all students and it just involves some student routines, which are quite different from the real enterprise management in content and complexity. Consequently, this will not do much for the formation of enterprise management capacity.

Therefore, the ways and methods for the management capacity cultivation in management majors seem to be a tough and urgent issue. Since there are a few researches in this field and no effective pattern for management capacity cultivation nowadays, this article aims at creating a new pattern for that.

\section{The Main Contents of Management Capacity}

Management capacity, especially that in enterprises, includes a variety of abilities in leadership, planning, decision making, project management, organization of resources, construction and operation of teams, personal communication and coordination, problem analysis and resolution, coping with conflicts, self-management, innovation and so on. Let's take project management as an example:

Here project management refers to the capacity to carry out strategic plans and convert those ideal targets into practice, which includes quite a lot of management ranges such as in time, range, cost, quality, human resources, potential risks, communication, purchase, contract and comprehensive management.

The following abilities should be included in project management capacity:

\subsection{The Ability to Lay Down Strategic Planning for Project Management}

Strategic planning is a process to form and conduct a decision about the future development of an organization, through which it will adapt itself to the constantly changing environment.

\subsection{The Ability to Divide a Project}

This specific ability refers to dividing a project in order to manage and control with greater convenience. Generally, project management can be divided into starting, planning, conducting, controlling and ending processes, each of which can be further divided into many subparts.

\subsection{The Ability to Integrate a Project}

The overall nature of a project calls for integrated management, in which different elements can be coordinated to realize the common target in performance, schedule and budget, hence accomplishing the ultimate goal of the whole project. Here, this ability can be further divided into the integration ability in project targets as well as processes. 
In our actual project management, the project manager is expected to regard the specific project as a whole in which the correlation among different parts as well as that between individual projects and their roots should be paid much attention to. Only with a clear idea about the general environment and project can a project manager produce a definite goal and reasonable plan for that.

\section{The Innovative Pattern for Management Capacity Cultivation of Management Majors}

\subsection{The Idea of Management Capacity Cultivation Pattern}

Guided by teachers, students can form their sub-teams voluntarily, of which they are planners and implementers. They are allowed to refer to materials, design their implementation plans for their projects and conduct their own management practice. Compared with the complicated course stuff, these planning and implementation activities are actual, comprehensive and creative. It is through designing their own projects and applying what they have learnt into them that management majors come to understand the core of management and form their actual management capacity.

As is well known, the knowledge obtained in one's own experience tends to be unforgettable and become one part of his ability. Accordingly, students will form their management capacity by acquiring their personal experience from those elaborately-designed activities and virtual circumstances and sharing their individual experience with each other to enhance their understanding under the instruction of teachers. This team project design and management is an advanced independent leaning style, which applies not only to classrooms but also outside them. As a result, students will have their innovation, organization, communication, expression, project management capacities fully developed as well as acquire basic management knowledge.

\subsection{The Concrete Process of Cultivating Management Capacity}

Teachers make a general planning to produce a general project with specific requirements. For example, in accordance with the characteristics of the city they live, the teacher can put forward with a project plan to establish the brand of his city. Thus, with a clear idea about the actual value and feasibility of this project, students will not conduct their creation blindly. Their knowledge and sense of vocation about the city they live will inspire their interest and passion to practice their creative ability in such a real-life project.

Students form their sub-teams of 5 to 10 voluntarily to plan and design their individual sub-projects based on their interest, specialties and reality. In each sub-team a project manager should be chosen to take charge of the organization and distribution of team activities. During the whole process, every participant will obtain some relevant management theories, knowledge and skills, practise their communicative ability and cultivate their self-confidence and sense of cooperation.

After their projects proved feasible, efforts should be made to clarify their targets and to lay down feasible plans and action details. Students in the same team are expected to unite to achieve the common goal with their clearly-divided responsibilities and rights. They will take some virtual posts such as project manager, financial minister, sales minister, personnel minister and so on to conduct strategic analysis and control the quality, time, risk of their projects.

Teachers should organize some students to design their project management website, on which all teachers and students can comment on the achievements in different periods made by individual teams and give immediate advice for amendment.

When conducting their projects, team members can discuss and analyze the problems they come across and solve them by trying a variety of methods according to what they have learnt in class.

A representative appointed by each team reports their periodic summaries to the whole class.

Every week, all students and teachers will be given a report about what is going on in each project and give their advice and comment.

At the close of a term, each team is expected to summit their overall project report. Teachers will give a comprehensive assessment about their report, organize a lecture tour for these teams around the whole school and publish invitations for investment in these projects with the hope to convert them into actual ones.

\section{The Actual Effect of the New Management Capacity Cultivation Pattern}

Actually, our above practice has led to obvious effect:

(1) Students' enthusiasm for learning has been inspired and their leaning and innovative abilities have been improved. Students' enthusiasm for learning can be inspired by converting theoretical knowledge into interesting team activities. Although the depth and level of their researches are limited by their knowledge and ability, students' 
creativity and individuality and their sense of innovation can be fully exerted in their independent comprehensive practice. Consequently, innovative forms bring about innovative contents and methods.

(2) Students' sense of participation, satisfaction and responsibility as well as communicative abilities has been developed. During the whole process, as active participants, students have to take an active part in their team work before, during and after class, hence exerting their organization, expression and personal communication abilities, enhancing their self-confidence and developing their sense of satisfaction. In addition, the leaning, questioning and stimulation among different project teams will encourage students to apply their theoretical knowledge into actual practice, during which members from different teams will exchange their ideas and opinions, hence developing their communicative skills.

(3) Students' team spirit and sense of cooperation have been developed in their team activities, during which project managers ill arrange every member's task reasonably in order to cooperate to accomplish their team tasks faster and better.

(4) Students' ability in analyzing, solving problems and exerting their knowledge in a comprehensive way has been enhanced. Through their team activities, students will obtain practical methods and abilities to employ what they have learnt to reflect on and solve problems instead of just empty and abstract theories. In this way, their abilities in contact, making decisions and employing management knowledge have been improved.

(5) Students' expression ability has been improved greatly. In their project reports every week, they have to stand in front of the whole class to report their project achievements with multimedia courseware. At first, some students only bury themselves into their written speeches without confidence to face the class and proper rhythm. However, with more exercise, the example set by those excellent students and instruction from teachers, they tend to be calmer and controlling in their looks, intonation, tempo, gesture and other aspects.

(6) Students' organization ability has been improved. In their organized teams, all members have their respective responsibilities and rights as well as cooperation. Therefore, in the distribution, implementation and examination of the tasks in every period, their organization ability has been fully improved.

To sum up, this new pattern, characterized by the multi-dimensional cultivation of students' management capacity, has exceeded the convey of textbook knowledge and have converted teachers' roles into not only the organizer, instructor, promoter and evaluator but also the developer, designer and director of students' general learning project. And students are the designer, organizer, implementer of their sub-subjects. With the concrete guidance of their teachers, students will unite to carry out the design and practice of their projects with clear division of labor and common efforts. By communicating, assisting, encouraging and appreciating each other, all these teams will accomplish their general goal successfully, in which students' professional knowledge will get expanded and improved and their abilities in leadership, planning, decision making, project management, organization of resources, construction and operation of teams, quality management, personal communication and coordination, problem analysis and resolution, coping with conflicts and self-management will be enhanced. In addition, students' creativity and interest in study will be inspired, resulting in higher efficiency.

\section{References}

Gao, Wen. (2002). A Discussion on Teaching Patterns. Shanghai Education Press.

Ma, Lan. (2004). Value Connotation of Cooperative Learning. Course, Teaching Material and Teaching Method. (4).

$\mathrm{Xu}$, Xiaozhou. (2002). On the Team Cooperation Learning Style in Undergraduate Teaching of Research-type Universities. China Higher Education Research. (5).

Zeng, Qi. (2002). Reflection and Outlook of Cooperative Learning Research. Theory and Practice of Education. (3).

Zhang, Qinxia. (2001). The Team Spirit of Confucianism and the Cultivation of College Students' Sense of Team. Journal of Shannxi Education Institure. (1). 